\title{
A Quantitative Survey on Iranian English Learners' Attitudes toward Varieties of English: World English or World Englishes?
}

\author{
Reza Pishghadam (Corresponding author) \\ English Department, Ferdowsi University of Mashhad \\ PO box 9177948974, Park Square, Ferdowsi University, Mashhad, Iran \\ Tel: 98-915-307-3063_E-mail: rpishghadam@yahoo.com \\ Fahime Sabouri \\ English Department, Ferdowsi University of Mashhad \\ PO box 9177948974, Park Square, Ferdowsi University, Mashhad, Iran \\ Tel: 98-511-761-4188 E-mail: fahime.saboori@gmail.com
}

Received: October 24, 2010 Accepted: November 29, 2010 doi:10.5539/ells.v1n1p86

\begin{abstract}
This empirical study seeks to investigate Iranian English learners' attitudes toward different varieties of English in relation to the perspective of the theory of "World Englishes". Making use of a modification of matched guise technique, 165 English learners were asked to listen to a text read by native speakers of the following accent groups: British, Persian, American, and Arabic. Subjects, then, recorded their attitudes toward each of the readers using a semantic differential scale. Based on the results, the learners considered American accent to be quite superior to the others. They, also, considered people with American accent to be better teachers. These findings reveal the fact that Iranian English learners still believe in the existence of a World English rather than World Englishes.
\end{abstract}

Keywords: Attitude, Native speaker, Standard English, World Englishes

\section{Introduction}

English as the language of international communication has for long been, and still is, spreading all over the world, and since any transmission of language brings about transformation (Widdowson, 2003), this spread has resulted in the existence of different varieties of English, each as a consequence of English contact with a certain language, culture and people. The interesting point is that the speakers of these new Englishes who use English to communicate with fellow non-native speakers far outnumber its native speakers (Widdowson, 2003).

The coinage and promotion of the term World Englishes is mainly associated with Kachru (1982). The underlying philosophy of Kachruvian approach argues for the "importance of inclusivity and pluricentricity in approaches to linguistics of new varieties of English" (Bolton, 2004, p. 367). In addition, in an attempt to empower new Englishes, this theory calls the labels native speaker and native and standard English into serious question and denies any special status for them.

As for the context of ELT, the learners all over the world are, today, faced with different varieties of English and naturally develop attitudes toward them. Now, what is the significance of such attitudes to the theory of "World Englishes" and why should they matter?

Timmis (2007) argued that the variety of a target language a learner acquires and prefers to speak in is influenced by his or her attitude towards that variety. In other words, the more positive your attitude is toward a certain variety, the more motivated you get in conforming to it. The problem here, based on the ideology of World Englishes, pops up when such conformity is not in line with your needs and motivations for learning English, i.e., you do your best to learn that variety with all its details simply because it is said to be the native and standard one. Still, a more important problem is that of identity. It follows that when a learner considers a certain variety to be the best or standard one and thus emphasizes on sounding like its native speaker, his or her cultural identity gets at stake.

The present study seeks to investigate Iranian English learners' attitudes toward different varieties of English in relation to the perspective of the theory of "World Englishes". 


\section{Theoretical background}

\subsection{Theory of "World Englishes"}

According to Bhatt (2001), World Englishes paradigm discusses the global spread of English and the large number of functions it has taken on with increasing range and depth in diverse sociolinguistic settings around the world. This paradigm particularly emphasizes on multilingualism, multicultural identities, multiple norms of use, and bilinguals' creativity. Moreover, having its theoretical and philosophical foundations in liberation linguistics, it severely problematizes the sacred cows of the traditional theoretical and applied linguistics including interference, interlanguage, native speaker, speech community, ideal speaker-hearer, Standard English, and traditional English canon.

Davis (2004), also, defined World Englishes as a term used to "legitimate the Englishes spoken in the British non-white colonies" and explained that the ideology behind it denies a special status for the native speakers of metropolitan English varieties and complains about these native speakers' discriminations against users of world Englishes (p. 442).

World Englishes has its philosophical roots in the two dominant schools of thought of the present time, i.e., Postcolonialism and Postmodernism.

Postcolonialism, according to Bressler (2007), emerges from colonialization period in the 19th century when Great Britain was "the largest colonizer and imperial power" in the world (p. 236). But the political, social, economic and ideological domination of England gradually started to disappear by the turn of the century through a process called decolonization, which reached its peak in 1950 by the independence of India. It was the birth of postcolonialism as a liberation movement. The aim of postcolonialism is to destablize the stablized institutions and in SLA, in particular, decolonizing the colonized ELT is its major concern. Some of its common themes include national identity, universality, resistance, appreciation of differences, and protection of indigenous languages and cultures. Postcolonialism is much similar to deconstructionism and postmodernism in its subjects and concerns.

Postmodernism in philosophy refers to a belief in the death of metanarratives (universal truth or grand theories such as Nazism, Fascism, and Marxism) and claims that no one can ever find the ultimate truth (Pishghadam \& Mirzaee, 2008). Contrary to modernism in which man is considered to be the center of the universe and the ideas of "the best" and absoluteness are possible, postmodernism believes in a world with no center, i.e., everything is relative and "the best" and "the perfect" have no place in it. It also moves toward divergence by the appreciation of differences.

There are different models of World Englishes but the one which best suggests the existence of Englishes, rather than one standard native English, is that of Kachru. His model was first published in 1985 and represents "the types of spread, the patterns of acquisition, and the functional domains in which English is used across cultures and languages" (Widdowson, 2003, p. 34). This model describes the global situation of English in terms of three concentric circles (Bhatt, 2001; Mesthrie \& Bhatt, 2008; Bolton, 2004; Kachru \& Nelson, 1996; Timmis, 2007; Widdowson, 2003): The Inner Circle countries are the traditional bases of English where English is the primary or dominant language and is acquired as the mother tongue. The U.S., Britain, Australia, Canada and New Zealand belong to this circle. The Outer Circle includes countries with long history of colonization, where English has official and institutional functions and is used both as an intra and international language. India, Nigeria and South Africa belong to this circle. And finally, the Expanding Circle comprises countries with increasing number of English speakers in which English is regarded as a foreign language and has no established social role in the community; yet, its functional domains are expanding rapidly. It includes China, Iran, Japan and Korea.

As mentioned earlier, the ideology of World Englishes calls the label native speaker into serious question and strongly denies a special status for it. It specially opposes the prevailing view that native speakers are necessarily better at speaking English and hence they would make better English teachers (Jenkins, 2003). Moreover, it argues that since English is used for international communication and is, thus, used among speakers from different nationalities, it simply makes no sense to talk of its non-native speakers. This argument gets even more powerful when one considers the ever increasing situations in which English is used as a lingua franca among its L2 speakers rather than between its L1 and L2 speakers.

Representing this view, Jenkins (2003) listed some arguments against the use of the term native and non-native speaker of English, including: its assuming monolingualism to be the world's norm while the majority of people are bi- or multilingual, its disregarding the lingua franca function of English, its being offensive for the proficient users of English to be labeled as non-native, and more importantly, by proposing a simplistic view of what constitutes error in English language use, its causing problems with the international English testing since it implies an 
irrelevant native standard reference point against which the users of all other varieties of English should be tested.

Cook (1995), as well, made attempts to empower non-native speakers by proposing his multi-competence model (cited in Brown, 2007). According to the main tenet of this model, L2 users are quite superior to monolingual native speakers and, thus, should not be compared to them; but should be considered in their own right. Such superiority lies in the fact that their mind is much more flexible than that of native speaker since they have access simultaneously to two competences rather than one; therefore, they have higher language and culture awareness.

Similarly, Widdowson (2003) strongly denied the native speakers' claim of the ownership of English language and their right to determine how it should be spoken around the world. In his book Defining Issues in English Language Teaching, he argued that the custodians of Standard English are not in fact natural native speakers but they are a minority of people, a particular self-elected subset of educated native speakers who have the power to impose this standard variety.

And as for the ownership of English, Widdowson (2003) did not deny the dual character of languages of every variety, i.e., performing communicative as well as communal functions, but asserted that no single community and culture has a right to claim the ownership of English explaining that "the very fact that English is an international language means that no nation can have custody over it" (p. 43).

In addition, one of the most important achievements of World Englishes in the last three decades has been to challenge the standard language ideology and replacing it by the liberation linguistics ideology (Bolton, 2004; Bhatt, 2001). The standard language ideology, according to Bolton (2004), is the traditional view in English studies which has awarded the American and British English the authority to provide and prescribe the norms of usage in all international English using contexts.

This tension between the prescription of a world standard English and the legitimacy and autonomy of world Englishes calls to mind the double-voicedness of Bakhtin's (1994) centripetal and centrifugal forces. Centripetal forces, as a modernist feature, are those calling for centralizing, homogenizing and convergence, which in the present context, contribute to the conformity to an authoritative and prescriptive standard variety which is believed to be the best. On the other hand, centrifugal forces, as a postmodernist feature, involve decentralizing and divergence and thus appreciate the diverse features and functions of English worldwide.

As pointed out earlier, liberation linguistics severely confronts the traditional Standard English ideology, in an attempt to legitimate and empower the new varieties of English as well as their speakers.

Representing such liberation ideology, Milroy and Milroy (1999) argued that prescribing a standard variety is in fact bestowing prestige to just one variety at the expense of suppressing all the others (cited in Davis, 2006).

Widdowson (2003) argued that the main importance of Standard English lies in a belief in its guaranteeing effective communication and standards of intelligibility. In his view, Standard English, which is usually defined in reference to its grammar and lexis, is primarily a written variety sanctioned for institutional use. Furthermore, he believed that Standard English is a shibboleth, marking the right sort of person. He elaborated on this issue arguing that while grammatical conformity, due to the in-built redundancy of language, is not crucial for effective communication, Standard English places much importance on it (rather than on lexis). The reason, according to Widdowson, is that grammar "is so often redundant in communicative transactions that it takes on another significance, namely that of expressing social identity" and so adopts the role of a distinguisher between members of the community and the outsiders (p. 39). The startling fact here is the existence of an implicit obligation of the membership of this community. In other words, you have just two choices: either you become a member of this community and enjoy its privileges including access to the institutions under its control, or, by persisting in your non-standard ways, you are marginalized and your ungrammatical speech and bad-spelt writing are assigned less importance and are not taken seriously.

Trudgill and Hannah's (1994) definition of Standard English is in line with that of Widdowson. Based on this definition, Standard English is usually used in writing, and spoken by educated speakers of English and "refers to grammar and vocabulary (dialect) but not to pronunciation (accent)" (p. 1, cited in Widdowson, 2003, p. 44).

Furthermore, Halliday (2006) laid stress on the fact that the standard variety has "no intrinsic value" and that it is "just another dialect, but one that happened to be wearing a fancy uniform" (p. 350).

Finally, Widdowson (2003) striped the attitudinal goodness totally away from Standard English by noting the double standards concerning the issue. He elaborated on it explaining that the stability implied by Standard English is in contrast with the dynamic nature of language and that while Standard English calls for conformity, "proficiency only 
comes with nonconformity" (p. 42). So you are proficient in English to the extent that you do not conform to Standard English and do not submit to what it dictates to you. In other words, mastery means taking the possession of the language, bending it to your advantage, developing innovations in it, and being able to speak your mind rather than speaking the language.

\subsection{Iran's ELT}

English Language in Iran is often learned through imitating a particular variety of English and most of the times your proficiency in English is evaluated according to such imitation, i.e., the more you achieve a native-like accent, the more proficient you are considered to be. Among different varieties of English just two are valued in Iran; in other words, it is generally believed that American and British Englishes are the best since they represent Standard English, the one spoken and understood most easily by its native speakers. Furthermore, it seems that having a native-like mastery of either of these two varieties has turned into a criterion for recruitment of English teachers.

The startling fact here is that just a tiny percent of these learners will ever have a chance to communicate with native speakers (Kirkpatrick, 2007). The great majority of others need English either to communicate with fellow non-natives or to be able to read different books and journals in English. So the question which remains to be reflected on is that: What is the use of such great emphasis on, and spending so much time and energy in acquiring these so-called standard varieties of English?

Not only does it demotivate those who fail to do so in the EFL context of Iran, but also it has exploitative effects on the learners who manage acquiring it after great effort. Recent research has shed light on some of such effects on the latter group. From a sociological perspective, Pishghadam and Kamyabi (2008), provided support for the direct link between the tendency and effort of the learners to achieve a native-like accent and their deculturation. Taking the same perspective, Pishghadam and Navari (2009) argued that, regarding the dominant conditions of education in Iran, the contact between two languages does not necessarily lead to cultural enrichment and that one of the languages might suffer cultural derichment, instead. Akhoondpoor (2008), in a similar vein but from a different point of view, discussed the psychological hindering effects of such perfectionism on the learners' performances.

This way of learning English through adopting an exonormative model and imitating it in all its details limits people's creative use of language and makes them turn into a tool for it, that is, what is done through linguistic imperialism. But the case must be the other way round, i.e., English as an international language must be a valuable instrument at disposal of people with different nationalities in order to express their way of thinking and present their culture through it. This view of English is in line with that of Crystal (2003), mentioned in his book English as a Global Language, in which he calls for adopting a functional account of English, the one that considers English as a precious tool for people to achieve their goals and the primary means of getting a global presence and being heard by the whole world.

Some countries, in accordance with this view, have already developed their own varieties of English, generally known as New Englishes, through acculturation and indigenization, i.e., influencing English language by their local cultures and languages (Kirkpatrick, 2007). This way they have developed a kind of nativised English which best suits their context of use, reflects their nationality, and is capable of expressing their own experience and way of thinking. The remarks of the Nigerian writer, Chinua Achebe, best highlights the need for such nonconformity in the form of modification of the international language:

I feel that English language will be able to carry the weight of my African experience ... But it will have to be a new English, still in communication with its ancestral home but altered to suit its new African surroundings. (Achebe, 1975, p. 62, cited in Widdowson, 2003, p.42)

While this is the case with other countries of the world, it seems that most of the Iranian learners and teachers still stick to their beliefs in the existence of Standard English, still consider American and British Englishes superior to other varieties, evaluate and are evaluated based on their native-like mastery of them, and keep on spending a great part of the time and energy, devoted to their learning English, in strict immitation of either of these varieties.

"World Englishes" is a relatively new theory, which has gained its worldwide currency only in the late 20th and early 21st centuries (Bolton, 2004). Having its philosophical roots in postmodernism and postcolonialism, this theory has remained somehow obscure in the modernist educational context of Iran, and as far as the researcher knows, there has been no study conducted in Iran in the field of English teaching and learning concerning "World Englishes". So, due to this paucity of research in the educational context of Iran in this field, this study is aimed at revealing whether the main tenet of World Englishes -the existence of world Englishes rather than a World English -has adherents among English teachers and learners. 


\section{Methodology}

\subsection{Participants and setting}

This study was conducted on 165 participants, who were learners in different English institutes of Mashhad. They consisted of 61 males and 104 females, within the age range of 18 to 30. One of the qualifications needed for the English learners to be chosen as the participants of this study was their level of proficiency, i.e., they needed to be at intermediate or higher levels, since it is believed that at such levels they have already established a sense of what different varieties of English are, formed attitudes toward these varieties and have probably selected one as their own model. The researcher relied on the institutes' placement tests in determining the learners' level of proficiency. The participants were not chosen randomly from a larger population and the two criteria for choosing them were simply accessibility and their tendency to cooperate.

\subsection{Instrumentation}

The instrument used in this attitude survey was a modification of the matched guise technique.

The matched guise technique - developed at McGill University by Lambert, Hodgeson, Gardner, and Fillenbaum (1960) -as a subjective reaction test is employed to reveal participants' attitudes toward other people's traits based solely on tape-recorded speech of individuals who are bilingual or bidialectal (Anisfeld, Bogo, \& Lambert, 1962; and Webster \& Kramer, 1968, cited in Alford \& Strother, 1990). Participants show their reaction to each characteristic of each speaker by marking an odd-numbered scale. Each segment of the scale is assigned a number (usually 1 to 7) and then averages of each characteristic are calculated.

However, a modification of the matched guise technique -which has also been used by Anisfeld, Bogo, \& Lambert (1962); Markel, Eisler, and Reese (1967); Tucker and Lambert (1969); Carranza and Ryan (1975); Ryan and Carranza (1975); Williams, Hewett, Miller, Naremore, \& Whitehead, (1976) (all cited in Alford \& Strother, 1990) was used in the present study. In this modification, speakers from different accents speak with their own normal accents and, thus, there is no need to change their voice quality or style in an attempt to distinguish among the various accents. That is why this technique enjoys natural, rather than counterfeit accents with the aim of representing actual stereotypes of the speakers.

The reliability of the questionnaire associating with the matched guise technique was checked by Alford and Strother (1990) using a two-tailed Pearson Product Moment Corrolation for reliability $(\mathrm{r}=.455)$. Its validity was, also, substantiated. In addition, to test for the reliability of the questionnaires in this study a Cronbach's Alpha was, also, calculated for each speaker to determine the degree of consistency in the way participants rated each speaker ( $\mathrm{r}$ $=.714$ to .821 ).

\subsection{Procedure}

The data collection was started in January 2009 and took around two months. As stated earlier, a modification of the matched guised technique was utilized in order to reveal the learners' attitudes toward 4 English accents. To this end, the participants listened to a taped text dealing with the culturally neutral topic of making a comment about some TV programs (for the text see appendix A). The text was a relatively short and simple one chosen from an elementary textbook (Collie \& Slater, 1995) and was read, in a random order, by four native speakers of the following English accent groups: British, Persian, American, and Arabic. By controlling for the gender, age and voice quality of the speakers -they were all males and about the same age $(25,26,30,31)$-and, also, for their reading speed, word choice and syntax - by reading the same text -every attempt was made to leave accent as the only variable under consideration in this part. After listening to each speaker, the participants were asked to evaluate personality characteristics of that speaker, using speech style and voice characteristics as cues, by marking their responses on a 7-point semantic differential scale which was adapted from Alford and Strother (1995).

Each participant's reactions to each speaker were recorded in the form of a numerical index for each accent. In the ranking, a score of 1 was the most negative and 7 was the most positive. The index was obtained by summing the ratings for each trait for each speaker (for the scale see appendix B).

\section{Results}

To determine participants' reactions to the 4 accents, several statistical analyses were utilized including a one-way ANOVA (to determine the significance of difference) plus a Scheffe post hoc test (to spot the locations of difference) for each of the 12 characteristics present in the questionnaire and for the overall rating of each speaker as well.

Table 4.1. reveals a significant difference among the four groups regarding their overall rating. 
As evident in table 4.2., in the rating of the characteristics: very intelligent/not very intelligent, well educated/poorly educated, ambitious/lazy, self-confident/not self-confident, professional/ nonprofessional, good family training/poor family training, a good teacher/not a good teacher, the American speaker received the highest ranking. The second and third rankings were, successively, accorded to British and Persian speakers. And, the last ranking was assigned to the Arabic speaker.

American $>$ British $>$ Persian $>$ Arabic

This order, however, was different for the other five characteristics. For gentle/harsh, for example, participants accorded the highest rating to the American speaker, the second ranking to the British one, the third ranking to the Persian speaker, and the last ranking to the Arabic one.

American $>$ Persian $>$ Arabic $>$ British

As for trustworthy/untrustworthy, the highest ranking was assigned to the American speaker, with the Persian and British speakers tying for the second place. The Arabic speaker received the lowest ranking.

\section{American $>$ British \& Persian $>$ Arabic}

In addition, the highest friendliness ranking was assigned to the American speaker and the second highest ranking to the British speaker, with the Persian and Arabic speakers tying for the last place.

\section{American $>$ British $>$ Persian \& Arabic}

Furthermore, participants considered the American speaker as the most sincere one, the Persian speaker as the second most sincere, with the British speaker somewhere in the middle (having a sincerity level close to those of both the American and the Persian speaker). They also accorded the lowest sincerity ranking to the Arabic speaker. American > Persian > Arabic; British > Arabic

Also, participants considered the American speaker as the most patient one, the Arabic speaker as the second most patient one, with the Persian speaker somewhere in the middle (having a patience level close to those of both the American and the Arabic speaker). They also accorded the lowest patience rating to the British speaker.

\section{American $>$ Arabic $>$ British ; Persian $>$ British}

Finally, the American speaker (5.476) received the highest overall rating. The British (4.251) and Persian (3.483) speakers were accorded the second and the third overall ratings. And the lowest overall rating was assigned to the Arabic speaker (2.748). Thus, put simply, the participants appreciated the American accent more than the British, the British more than the Persian, and the Persian more than the Arabic one. To state the obvious, the order of this overall ranking corresponds to the most frequent one in the ranking of the twelve formerly mentioned characteristics, namely: American > British > Persian > Arabic

As stated earlier, the results of the questionnaires are highly indicative of the fact that the American English is looked up to and considered quite superior to the other accents of English by Iranian English learners. The main problem with such view is that, as Kirkpatrick (2007) put it, "accents are closely bound up with feelings of personal and group identity" (p. 37); thus, the English learners who aim at acquiring a native accent, due to considering it as the best one, are very likely to be subject to deculturation and loss of local identity (Pishghadam \& Kamyabi, 2008).

Here, it is worth stating the interesting question Kachru and Nelson (1996) asked after referring to the same link between accent and identity; "If a typical American has no wish to speak like or be labeled as a British user of English, why should a Nigerian, an Indian, or a Singaporean user feel any differently?" (p. 89); Now, regarding our case, the question is that: Why should an Iranian wish to speak like an American user of English?

Still, a very noteworthy point regarding such great positive attitude of English learners towards American accent and their consequent attempts at acquiring a native accent and sounding native-like is that most of English users in Outer and Expanding circle countries will never need English to communicate with native users (Kachru \& Nelson, 1996; Kirkpatrick, 2007; Mesthrie \& Bhatt, 2008). Iran, as an expanding circle country, is no exception and anyone with few years of experience in teaching English in Iran can easily get the idea that only a tiny percent of Iranian English learners will live or educate in a native English country and have contact with native speakers. So such great efforts and emphasis seem quite absurd.

\section{Conclusion}

The main result of this study, namely, Iranian English users' belief in American and British Englishes as the best varieties, has an outstanding macro-level ramification. This ramification involves Pishghadam and Mirzaee's (2009) claim that Iran's educational system still lives in the modernist era due to different reasons all emphasizing on 
unification such as teaching the same books all over the country and the existence of General Exam, to name a few. It unfortunately seems that their claim is completely true about Iran's ELT, as far as this study is concerned, considering the fact that most of our learners still believe in a world English rather than world Englishes and that the ideas of "the best" and "the perfect" and the importance of unification have their followers among them.

Also, the detailed descriptive results of the questionnaires clearly illustrated that people with the American accent were considered to be superior to others from different perspectives including psychological, sociological, etc. corresponding to the bipolar adjectives presented in the questionnaires. The possible reasons for such view among Iranian English learners are worthy of attention. The most important reason might be the unique status of the U.S. in the world today, i.e. its being a superpower and dominating the international business and markets, science, information technology, etc. A second possible reason can be the English learners' lack of knowledge about the present situation of English around the world, i.e. its stratification and realization in different varieties through indigenization and the fact that, today, the nonnative speakers of English far outnumber its native ones. Still, a third possible reason can involve the aesthetic aspect, namely, they have a positive view towards it simply because it sounds more beautiful and pleasing to them. Finally, another reason might be that most of our learners are perfectionists, so they consider one of the varieties to be the perfect one and do their best to acquire it.

Whatever the reason, the obvious point is that such way of looking up to a certain variety and longing for being labeled as its native speaker can lead to a faint local identity with a great potential and willingness for adopting its culture.

The most important implication of this study can be making both teachers and learners aware of the fact that there is no best and standard variety of English, i.e., American and British Englishes are two varieties of English just the same as the others with no higher status. As an immediate effect of this awareness they would stop trying to sound native-like. It would also prevent them from placing a very high premium on acquiring and conforming to American or British English. Such prevention, in turn, can have three noteworthy consequences:

First, learners would be relieved of their perfectionism and its psychological hindering effects, including high stress and constant dissatisfaction, on their learning. Second, learners would specify and focus on their needs and motivations in learning English and, based on them; they would either approximate to a certain variety or be satisfied with their own Persian accent. Third, learners would be less likely to be subject to loss of local identity and deculturation.

This study is limited in two noteworthy ways. Firstly, by employing a modification of the matched guise technique in order to utilize natural accents, this study used different speakers and, thus, could not control for the unique "personality cue value" every voice has (Webster \& Kramer, 1968, p. 239, cited in Alford \& Strother, 1990, p. 486). secondly, this study used learners, only, as its participants. So, further research should be carried out in order to see whether similar results will be obtained when conducting the research on teachers as well.

\section{References}

Akhoondpoor, F. (2008). On the role of learner perfectionism in second language learning success and academic achievement. Unpublished master's thesis, Ferdowsi University of Mashhad, Iran.

Alford, R. L., \& Strother, J. B. (1990). Attitudes of native and nonnative speakers toward selected regional accents of U.S. English. TESOL Quarterly, 24, 479-495.

Anisfeld, M., Bogo, N., Lambert, W. E. (1962). Evaluational reaction to accented English speech. Journal of Abnormal and Social Psychology, 65, 223-231.

Bakhtin, M. M. (1994). The Dialogue Imagination, (M. Holoquist \& C. Emerson, Trans.). In S. Dentith (Ed.), Bakhtinian thought: An introductory reader. London: Routledge.

Bhatt, R. M. (2001). World Englishes. Annual Reviews, 30, 527-550.

Bolton, K. (2004). World Englishes. In A. Davis, \& C. Elder (Eds.), The handbook of applied linguistics. Oxford: Blackwell. pp. 367-396

Bolton, K. (2006). Varieties of world Englishes. In B. B. Kachru, Y. Kachru, \& C. L. Nelson (Eds.), The handbook of world Englishes. Oxford: Blachwell. pp. 289-313

Bressler, C. E. (2007). Literary criticism: An introduction to theory and practice (4th ed.). NJ: Pearson education. Brown, H. D. (2007). Principles of language learning and teaching (5th ed.). White Plains, NY: Pearson Education. 
Carranza, M. A., \& Ryan, E. B. (1975). Evaluative reactions of bilingual Anglo and Mexican American adolescents towards speakers of English and Spanish. International Journal of Sociology of Language, 6, 8-104.

Collie, J., \& Slater, S. (1995). True to life elementary (class book). Cambridge: Cambridge University Press.

Cook, V. (1995). Multi-competence and the effects of age. In D. Singleton \& Z. Lengyel (Eds.), The age factor in second language acquisition. Clevedon, UK: Multilingual Matters. pp. 52-58

Crystal, D. (2003). English as a global language (2nd ed.). Cambridge: Cambridge University Press.

Davis, A. (2004). The native speaker in applied linguistics. In A. Davis, \& C. Elder (Eds.), The handbook of applied linguistics. Oxford: Blackwell. pp. 431-450

Davis, D. R. (2006). World Englishes and descriptive grammars. In B. B. Kachru, Y. Kachru, \& C. L. Nelson (Eds.), The handbook of world Englishes. Oxford: Blackwell. pp. 509-527

Halliday, M. A. K. (2006). Written language, standard language, global language. In B. B. Kachru, Y. Kachru, \& C. L. Nelson (Eds.), The handbook of world Englishes. Oxford: Blackwell. pp. 349-366

Jenkins, J. (2003). World Englishes: A resource book for students. New York, NY: Routledge.

Kachru, B. B. (Ed.) (1982). The other tongue: English across cultures. Urbana, IL: University of Illinois Press.

Kachru, B. B. (1985). Standards, codification and sociolinguistic realism: The English language in the Outer Circle. In R. Quirk, \& H. Widdowson (Eds.), English in the world: Teaching and learning the language and literature. Cambridge: Cambridge University Press.

Kachru, B. B., \& Nelson, C. L. (1996). World Englishes. In S. L. McKay, \& N. H. Hornberger (Eds.), Sociolinguistics and language teaching. Cambridge: Cambridge University Press. pp. 71-102

Kirkpatrick, A. (2007). World Englishes: Implications for international communication and English language teaching. Cambridge: Cambridge University Press.

Lambert, W. E., Hodgeson, R. C., Gardner, R. C., \& Fillenbaum, S. (1960). Evaluational Reactions to spoken languages. Journal of Abnormal and Social Psychology, 60(1), 44-51.

Markel, N. N., Eisler, R. M., \& Reese, H. W. (1967). Judging personality from dialect. Journal of Verbal Learning and Verbal Behavior, 6, 33-35.

Mesthrie, R., \& Bhatt. R. M. (2008). World Englishes: The study of new varieties. Cambridge: Cambridge University Press.

Milroy, J., \& Milroy, L. (1999). Authority in language: Investigating standard English, (3 ${ }^{\text {rd }}$ ed.). London/New York: Routledge.

Pishghadam, R., \& Kamyabi, A. (2008). On the relationship between cultural attachment and accent mimicry. Unpublished manuscript, Ferdowsi University of Mashhad.

Pishghadam, R., \& Mirzaee, A. (2008). English language teaching in postmodern era. TELL, 2, 89-109.

Pishghadam, R., \& Navari, S. (2009). Cultural literacy in language learning: Enrichment or derichment? A paper presented at UITM of Malaysia.

Timmis, I. (2007). The attitudes of language learners towards target varieties of the language. In $\quad$ B. Tomlinson (Ed.), Language acquisition and development . pp. 122-139.

Trudgill, P., \& Hannah, J. (1994). International English (3rd ed.). London: Edward Arnold.

Tucker, G. R., \& Lambert, W. E. (1969). White and Negro listeners' reactions to various American-English dialects. Social Forces, 47, 463-468.

Webster, W. G., \& Kramer, E. (1968). Attitudes and evaluational reactions to accented English speech. Journal of Social Psychology, 75, 231-240.

Williams, F., Hewett, N., Miller, M., Naremore, R. C., \& Whitehead, J. L. (1976). Explorations Of the linguistic attitudes of teachers. Rowley, MA: Newbury House.

Widdowson, H. D. (2003). Defining issues in English language teaching. Oxford: Oxford University Press. 
Table 4.1 Results of one-way ANOVA for the overall rating of the four accents

\begin{tabular}{|c|c|c|c|c|c|}
\hline & Sum of Squares & df & Mean Square & F & Sig. \\
\hline Between Groups & 672.495 & 3 & 224.165 & 319.114 & .000 \\
\hline Within Groups & 460.815 & 656 & .702 & & \\
\hline Total & 1133.310 & 659 & & & \\
\hline
\end{tabular}

Table 4.2 Results of Post Hoc Test and one-way ANOVA for the twelve characteristics and overall rating of the four accents

\begin{tabular}{|l|c|c|c|c|c|}
\hline \multicolumn{1}{|c|}{ Accents } & American & British & Persian & Arabic & p level \\
\hline Very intelligent/Not very intelligent & 5.61 & 4.27 & 2.88 & 2.25 & .00 \\
\hline Well educated/ Poorly educated & 5.86 & 4.50 & 3.34 & 2.15 & .00 \\
\hline Ambitious/ Lazy & 5.61 & 4.88 & 2.76 & 1.95 & .00 \\
\hline Self-confident/ Not self-confident & 5.93 & 5.04 & 3.41 & 2.56 & .00 \\
\hline Professional/ Nonprofessional & 5.72 & 4.48 & 2.67 & 1.93 & .00 \\
\hline Good family training/ Poor family training & 5.46 & 4.50 & 3.81 & 3.13 & .00 \\
\hline A good teacher/ Not a good teacher & 5.65 & 4.30 & 2.72 & 1.80 & .00 \\
\hline Gentle/ Harsh & 5.69 & 3.53 & 4.63 & 4.04 & .00 \\
\hline Trustworthy/ Untrustworthy & 5.28 & $4.40^{*}$ & $3.98^{*}$ & 3.08 & .00 \\
\hline Sincere/ Insincere & $5.00^{*}$ & $* 4.55^{*}$ & $4.39^{*}$ & 3.64 & .00 \\
\hline Friendly/ Unfriendly & 5.39 & 3.87 & $3.05^{*}$ & $2.62^{*}$ & .00 \\
\hline Patient/ Impatient & $5.05^{*}$ & 3.27 & $* 4.74^{*}$ & $4.26^{*}$ & .00 \\
\hline Overall rating & 5.47 & 4.25 & 3.48 & 2.74 & .00 \\
\hline
\end{tabular}

The stars $(* *)$ indicate the pair with no significant difference.

Appendix A

Dear Sir,

I'd like to make a comment about the programs and advertisements we see on TV: there are no positive images of old people at all. Young people on TV have a lot of money, good jobs and wonderful clothes. They travel in fast cars or planes and have exciting lifestyles. But what about the old people we see in programs or ads? They live alone, they are usually poor, they never go anywhere, they never do anything. I think the people who make programs should be more careful. Is that really what our society thinks of older people? Is that really what our young people can hope for in the future? Remember, we'll all be old one day -if we're lucky!

Yours faithfully,

Appendix B

\section{INSTRUCTIONS:}

1. You are required to evaluate the personality characteristics of the speakers by marking the part of the scale, which best represents your opinion.

2. There are no right or wrong answers. All answers are equally important.

Teacher 1

I think teacher 1 is/has ...

Very intelligent

Trustworthy

Poorly educated

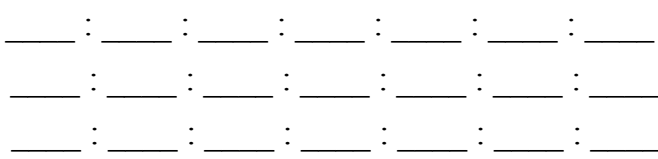

Not very intelligent

Untrustworthy

Well educated 
Lazy

Self-confident

Professional

Poor family training

Sincere

Unfriendly

Patient

Harsh

All in all:

A good teacher

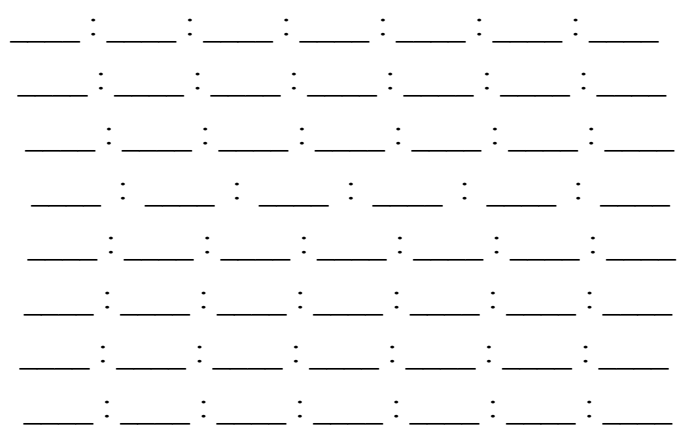

Ambitious

Not self-confident

Nonprofessional

Good family training

Insincere

Friendly

Impatient

Gentle

Not a good teacher 